\title{
Steroid-Induced Serous Retinal Detachment in a Patient with Polymyalgia Rheumatica
}

Hironori Takahashi ${ }^{1}$, Yuka Kasuya ${ }^{1}$, Shinji Makino ${ }^{1 *}$

${ }^{1}$ Department of Ophthalmology, Jichi Medical University, Shimotsuke, Tochigi 329-0498, Japan

DOI: $\underline{10.36347 / \text { sjmcr.2021.v09i04.010 }}$

| Received: 18.02.2021 | Accepted: 09.04.2021 | Published: 15.04.2021

*Corresponding author: Shinji Makino

Abstract

An 82-year-old man with polymyalgia rheumatica was referred for ophthalmological examination. On ophthalmic examination, his best-corrected visual acuity (BCVA) was 20/40 in the right eye and 20/20 in the left eye. Fundus examination was unremarkable in the left eye, but epiretinal membrane was observed in the right eye. There was no SRD on optical coherence tomography (OCT) in the right eye. The patient was treated with oral prednisolone (10 mg daily), and his symptoms subsided rapidly. However, 1 week after the administration of prednisolone, his right BCVA deteriorated to 40/200. OCT showed serous retinal detachment (SRD) involving the fovea in the right eye. We diagnosed our patient with steroid-induced SRD. SRD gradually improved with the reduction of the prednisolone dose. Clinicians should be aware of CSC development after glucocorticoid therapy. If possible, the glucocorticoid should be discontinued and replaced by an alternative.

Keywords: polymyalgia rheumatica, glucocorticoid therapy, optical coherence tomography.

Copyright $(\odot 2021$ The Author(s): This is an open-access article distributed under the terms of the Creative Commons Attribution 4.0 International License (CC BY-NC 4.0) which permits unrestricted use, distribution, and reproduction in any medium for non-commercial use provided the original author and source are credited.

\section{INTRODUCTION}

Polymyalgia rheumatica (PMR) is a common inflammatory rheumatic disease in older individuals and a common indication for long-term corticosteroid therapy $[1,2]$. Glucocorticoid therapy is a well-known risk factor for central serous chorioretinopathy (CSC), and exogenous glucocorticoids may cause CSC regardless of their route of administration, dosage, and duration [3-5].

Here, we report a case of steroid-induced serous retinal detachment (SRD) in an 82-year-old man with polymyalgia rheumatica.

\section{Case Report}

An 82-year-old man with PMR was referred for ophthalmological examination. His diagnosis of PMR was based on the following 2012 provisional classification criteria for PMR [1]: Morning stiffness duration > $45 \mathrm{~min}$, hip pain and limited range of motion, hip tenderness, shoulder pain and limited range of motion, shoulder tenderness, abnormal C-reactive protein level $(20.14 \mathrm{mg} / \mathrm{L})$ and erythrocyte sedimentation rate $(131 \mathrm{~mm} / \mathrm{h})$, negative rheumatoid factor, and negative anticitrullinated protein antibody. There were no visual symptoms. On ophthalmic examination, his best-corrected visual acuity (BCVA) was 20/40 in the right eye and 20/20 in the left eye. Slitlamp examination revealed mild bilateral cortical opacities of the lens. Fundus examination was unremarkable in the left eye, but epiretinal membrane was observed in the right eye. There was no SRD on optical coherence tomography (OCT) in the right eye (Figure 1A). The patient was treated with oral prednisolone (10 mg daily), and his symptoms subsided rapidly. However, 1 week after the administration of prednisolone, his right BCVA deteriorated to 40/200. OCT showed SRD involving the fovea in the right eye (Figure 1B). We diagnosed our patient with steroidinduced SRD. 

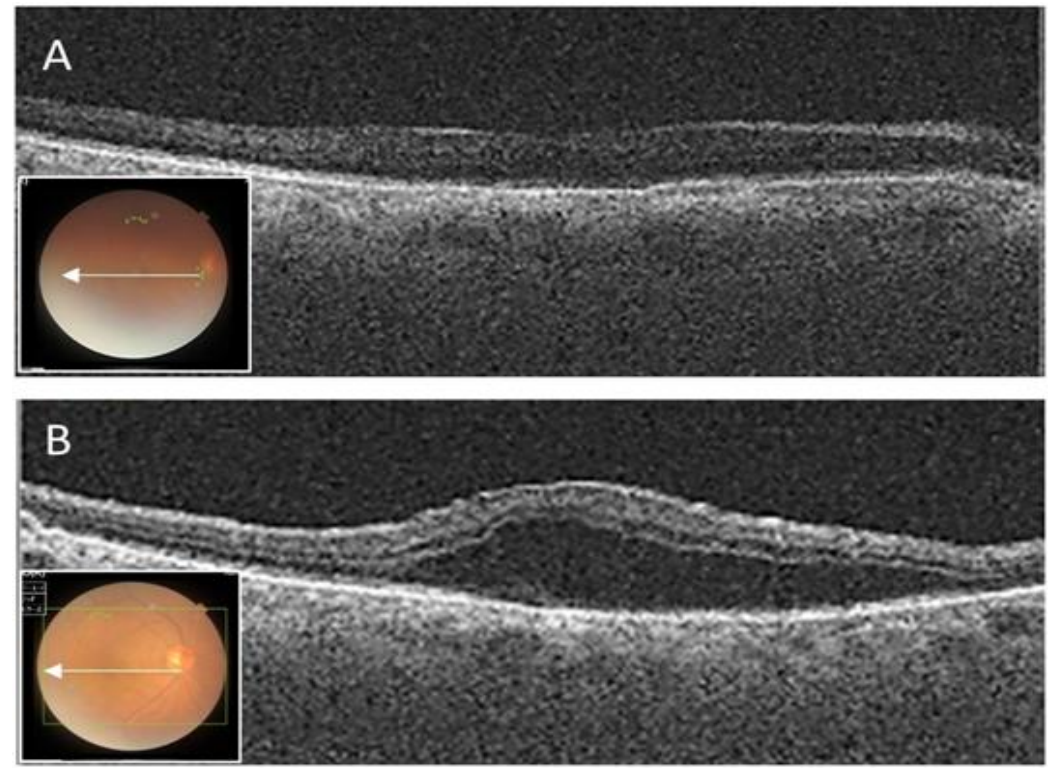

Fig-1: Optical coherence tomography images of the right eye in horizontal directions

The direction is shown in each inset. A: Initial visit; Serous retinal detachment (SRD) is not shown. B: One week after the administration of predonisolone; Marked SRD is developed.
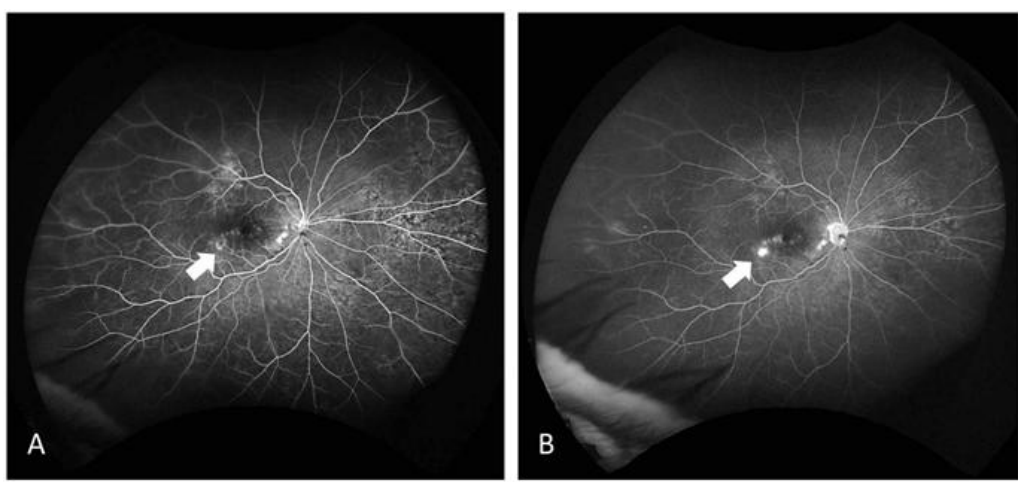

Fig-2: Fluorescein angiography of the right eye A: early phase, B: late phase

Note leakage with diffusion of the fluorescein and detachment of the macular retina. SRD gradually improved with the reduction of the prednisolone dose.

\section{DisCUSSION}

In this study, we present a case of steroidinduced SRD in an 82-year-old man with PMR. To our knowledge, there is only three reports of CSC associated with PMR [3, 6, 7] .

PMR is a common inflammatory rheumatic disease in older individuals and a common indication for long-term corticosteroid therapy $\left[\begin{array}{ll}1, & 2\end{array}\right]$. Glucocorticoid therapy is a well-known risk factor for CSC, and exogenous glucocorticoids may cause CSC regardless of their route of administration, dosage, and duration [3-5]. The risk exists with oral dosages of only $10-15 \mathrm{mg} /$ day, regardless of treatment duration. The time from glucocorticoid exposure to CSC development ranges from a few days to several years.
Fluorescein angiography confirmed the diagnosis of CSC based on leakage with the diffusion of the fluorescein. 


\section{Disclosure}

The author declares no conflict of interest.

\section{REFERENCES}

1. Dasgupta B, Cimmino MA, Kremers HM, Schmidt WA, Schirmer M, Salvarani C, Bachta A, Dejaco C, Duftner C, Jensen HS, Duhaut P. 2012 provisional classification criteria for polymyalgia rheumatica: a European League Against Rheumatism/American College of Rheumatology collaborative initiative. Arthritis \& Rheumatism. 2012 Apr;64(4):943-54.

2. Salvarani C, Cantini F, Hunder GG: Polymyalgia rheumatica and giant-cell arteritis. Lancet. 2008; 372: 234-245.

3. Bouzas, E. A., Karadimas, P., \& Pournaras, C. J. (2002). Central serous chorioretinopathy and glucocorticoids. Survey of ophthalmology, 47(5), 431-448.
4. Nicholson BP, Atchison E, Idris AA, Bakri SJ. Central serous chorioretinopathy and glucocorticoids: an update on evidence for association. survey of ophthalmology. 2018 Jan 1;63(1):1-8.

5. Ge G, Zhang Y, Zhang Y, Xu Z, Zhang M. Corticosteroids usage and central serous chorioretinopathy: a meta-analysis. Graefe's Archive for Clinical and Experimental Ophthalmology. 2020 Jan;258(1):71-7.

6. Geoffroy M, Afriat M, Fauconier M, Eschard JP, Salmon JH. Adverse effect of corticosteroid therapy: central serous chorioretinopathy. Joint bone spine. 2018 Jan;85(1):127-8.

7. Tittl MK, Spaide RF, Wong D, Pilotto E, Yannuzzi LA, Fisher YL, Freund B, Guyer DR, Slakter JS, Sorenson JA. Systemic findings associated with central serous chorioretinopathy. American journal of ophthalmology. $1999 \mathrm{Jul}$ 1;128(1):63-8. 